\title{
Improvement in quality of life in patients with Fistula-In-Ano, following surgical management, a prospective observational study
}

\author{
Chandrabose K. ${ }^{1}$, Nair V. ${ }^{2}$ \\ ${ }^{1}$ Dr. Karpagavel Chandrabose, Assistant Professor, Department of General Surgery, ${ }^{2}$ Dr.Velayudhan Nair, Assistant \\ Professor, Department of General Surgery, Dr. SMCSI Medical College, Karakonam, Trivandrum, Kerala, India.
}

Address for Correspondence: Dr. Karpagavel Chandrabose, Assistant Professor, Dept. of General Surgery, Dr. SMCSI Medical College. Karakonam, Trivandrum, Kerala. E-mail: drkarpagavel@gmail.com

\begin{abstract}
Background: Fistula-in-ano may lead to significant worsening of quality of life of affected person. But studies documenting the impact of treatment on quality of life are very limited in Indian population. Hence the current study was conducted with an objective of asseseing the improvement in quality of life in patients undergoing surgical management of fistuala-in-ano in a tertiary care teaching hospital in south India. Methodology: The current study was a prospective observational study, conducted in the department of general surgery of Dr. SMCSI Medical college hopital, between February and December 2016. A total of 45 subjects aged between 20 to 80 years, suffering from various types of fistual in ano, managed with surgical intervention were included in the study. Quality of life before and after surgery was assessed by GIQLI questionnaire. Results: Among the 45 subjects, $71.11 \%$ were males majority were aged between 41 to 60 years. The proportion of Inter sphincteric fistula was 48.88\% whereas Trans-sphincteric fistula and Supra sphincteric fistula were $33.33 \%$ and $17.77 \%$ respectively. Fistulectomy was conducted in $44.44 \%$ of cases. Fistulotomy and insertion of cutting setons were done in $31.11 \%$ and $24.44 \%$ cases. Mean values of symptoms pre and post-operative were 49.50 and 66.25 and the association was statistically significant $(\mathrm{P}=<0.01)$. Mean associated physical disease was 14.25 before surgery and the post-operative mean was 22.76 with a statistically significant mean difference $(\mathrm{P}=<0.01)$. Preoperative Mean values for emotions, social integration, and effects of treatment were 7.65, 8.26 and 3.00 respectively, whereas Post-operative means were 15.27, 14.40 and 3.65. There were statistically significant mean differences for Emotions, social integration and effects of treatment. Mean Total score of pre-surgery was 89.05 and post-surgery was 120.26 with statistically significant mean difference. ( $\mathrm{P}=<0.01)$. Conclusions: 1$)$ There is a significant improvement in the quality of life postoperatively in patients of Fistula in ano. 2) GIQLI score is an useful tool to assess the quality of life in Fistula in ano patients.
\end{abstract}

Key words: Fistula- in-ano, quality of life, GIQLI.

\section{Introduction}

A fistula-in-ano is an infected tunnel which communicates anal canal or rectum and is in continuity with a secondary opening in the perianal skin and these external openings may be one or more. The majority of anal fistulas have common pathophysiology and are caused due to the cryptoglandular infection but the complexity of pathology differs due to the involvement of sphincter [1]. Successful treating of fistula in ano is more difficult to surgeons and choosing of right surgery technique also more difficult because of its consequences like reoccurrence, profound fecal incontinence (FI) and impaired quality of life (QOL) [2]. There are multiple surgical methods available for anal fistula, however, Fistulotomy (FT) is the best therapeutic

Manuscript Received: $4^{\text {th }}$ March 2017

Reviewed: $14^{\text {th }}$ March 2017

Author Corrected: $23^{\text {rd }}$ March 2017

Accepted for Publication: $31^{\text {st }}$ March 2017 option, for structurally eradicating an anal fistula with a cure rate of $90 \%$ [3]. The tract of the fistula is laid open in Fistulotomy (FT). In Fistulotomy (FT) postoperative incontinence ranges from $4 \%$ to $62 \%$ in few reported incidences [4-6]. when the complexity of the perianal fistula tract increases the Severity of FI and showing a negative impact on QOL.

For high fistula-in-ano, a multitude of surgical treatment options is available like fistulotomy, fistulectomy, mucosal advancement flap (MAF), fibrin glue, fibrin plug, fistulotomy with the reconstruction of the sphincter complex and re-routing a high fistula to a more superficial level followed by fistulotomy. Optimal outcomes of any therapeutic option are the eradication of sepsis, cure and negligible effect on continence [7]. The impact of a 


\section{Original Research Article}

therapy on quality of life (QoL) is important and may influence patient's choice of different therapeutic interventions. The Gastrointestinal Quality of Life Index (GIQLI) questionnaire was developed by the surgeon Eypasch which contains 36 questions and was one of the best, widely used and assessed tool to assess the QOL in patients with Fistula -in -ano and relative diseases $[8,9]$.

Few of the existing studies focused on the assessment of QoL in patients with Fistula in ano but still, there is a gap which makes difficult to choice of surgery for both surgeons and patients $[8,10,11]$.

The aim of the current study was to assess the QoL in patients with recurrent fistula-in-ano and improvement in QoL after successful surgical treatment.

\section{Aims and Objectives}

- To assess the quality of life in patients with fistulain- ano before and after surgery.

- To assess the QoL of fistula in ano patients by using GIQLI tools.

\section{Materials and Methods}

Study setting: The study was conducted in Dr. SMCSI Medical College, Karakonam, Trivandrum, in the department of general surgery.

Study design: The study was a prospective observational study.

Study period: The study was conducted between February 2016 to December 2016.

Sample size: This study has included 45 patients.

\section{Inclusion criteria}

- All the subjects with age between 20 and 80 years, belonging to both sexes were included in the study.

- Patients with different types of fistula-in-ano (i.e. Inter sphincteric fistula, Trans-sphincteric fistula, Supra sphincteric fistula) were included.

- Patients who underwent either Fistulectomy, Fistulotomy and insersion of cutting sections were considered.

\section{Results}

A total of 45 subjects were included in this study.
Exclusion criteria: Patients suffering from other anorectal disorders which can affect the QOL were excluded.

Ethical considerations: The study was approved by the intuitional human ethics committee. Informed written consent was obtained from all study participants.

Confidentiality of the study participants was maintained throughout the study.

Study procedure: Selected data were elicited from the patients and recorded in structured proforma.

The data was collected on Socio demographic parameters like age, gender etc. and detailed history of presence fistula in ano as well as type of surgery which was performed; QoL of patients was assessed by using GIQLI questionnaire.

Study tools [12]: "The GIQLI questionnaire has 36 items that can be scored from 0 (worst) to 4 (best) to measure five dimensions of quality of life.

The five dimensions are:

- Symptoms (19 items)

- Associated physical disease (7 items)

- Emotions (5 items)

- Social integration (4 items)

- Effects of treatment (1 item)"

The differences in the pre- and post-operative GIQLI score total and score of each dimension were analyzed using Wilcoxon rank test.

Statistical analysis: Descriptive analysis of all the explanatory and outcome variables was done using frequency and proportion for categorical variables.

Postoperative and preoperative mean values of the GIQLI scores were compared by paired T-test. $\mathrm{P}$ value $<0.05$ was considered as statistically significant.

IBM SPSS version 21 was used for statistical analysis. 
Original Research Article

Table-1: Descriptive analysis of Sociodemographic parameters of the study population $(\mathrm{N}=45)$.

\begin{tabular}{|c|c|c|}
\hline Parameter & Frequency & Percentage \\
\hline \multicolumn{3}{|c|}{ Gender } \\
\hline Male & 32 & $71.11 \%$ \\
\hline Female & 13 & $28.88 \%$ \\
\hline \multicolumn{3}{|c|}{ Age Groups } \\
\hline 20 to 40 Years & 9 & $20.0 \%$ \\
\hline 41 to 60 Years & 24 & $53.33 \%$ \\
\hline 61 to 80 Years & 12 & $26.66 \%$ \\
\hline \multicolumn{3}{|c|}{ Types of fistula } \\
\hline Inter sphincteric fistula & 22 & $48.88 \%$ \\
\hline Trans-sphincteric fistula & 15 & $33.33 \%$ \\
\hline Supra sphincteric fistula & 8 & $17.77 \%$ \\
\hline Fistulectomy & Type of surgery & $44.44 \%$ \\
\hline Fistulotomy & 20 & $31.11 \%$ \\
\hline Insertion of cutting setons & 14 & $24.44 \%$ \\
\hline
\end{tabular}

The study population includes $71.11 \%$ males and $28.88 \%$ females. The majority of study participants were distributed in 41 to 60 years age group (53.33\%). Only $20 \%$ were under 20 to 40 years age group and $26.66 \%$ of participants in 61 to 80 years age group. The proportion of Inter sphincteric fistula was $48.88 \%$ whereas Trans-sphincteric fistula and Supra sphincteric fistula were $33.33 \%$ and $17.77 \%$ respectively. Fistulectomy was conducted in $44.44 \%$ of cases. Fistulotomy and insertion of cutting setons were done in $31.11 \%$ and $24.44 \%$ cases. (Table- 1 )

Table-2: Comparison of Preoperative and postoperative GIQLI scores in the study population (N=45).

\begin{tabular}{|c|c|c|c|}
\hline Parameter & $\begin{array}{c}\text { Preoperative } \\
\text { Mean + SD }\end{array}$ & $\begin{array}{c}\text { Postoperative } \\
\text { Mean + SD }\end{array}$ & P Value \\
\hline Symptoms & $49.50+10.11$ & $66.25+9.8$ & $<0.01$ \\
\hline Associated physical disease & $14.25+6.92$ & $22.76+7.03$ & $<0.01$ \\
\hline Emotions & $7.65+3.96$ & $15.27+5.54$ & $<0.01$ \\
\hline Social integration & $8.26+2.97$ & $14.40+3.20$ & $<0.01$ \\
\hline Effects of treatment & $3.00+1.09$ & $3.65+1.01$ & $<0.01$ \\
\hline Total score & $89.05+22.65$ & $120.26+22.36$ & $<$ \\
\hline
\end{tabular}

Mean values of symptoms pre and post-operative were 49.50 and 66.25 and the association was statistically significant $(\mathrm{P}=<0.01)$. Mean associated physical disease was 14.25 before surgery and the post-operative mean was 22.76 with a statistically significant mean difference $(\mathrm{P}=<0.01)$. Preoperative Mean values for emotions, social integration, and effects of treatment were 7.65, 8.26 and 3.00 respectively whereas Post-operative means were 15.27, 14.40 and 3.65. There were statistically significant mean differences for Emotions, social integration and effects of treatment. Mean Total score of presurgery was 89.05 and post-surgery was 120.26 with statistically significant mean difference. $(\mathrm{P}=<0.01)($ Table-2)

\section{Discussion}

The majority of Fistula- in- ano patients were facing worse QoL because of its reoccurrence after surgical treatment and long-term effects like fecal incontinence. QoL of fistula in ano patients was affected by not only because of physical problems but also integrated with some social aspects. Even though there was an advancement in surgery techniques no one is giving satisfactory results. Thus electing of surgery technique for fistula in ano was still a difficult job for both surgeons as well as patients. As per available literature few of the existing studies concentrated on this field, but our study focused on QOL of Fistula in ano patients by comparing pre and postoperative mean values of GIQIL scores.

As per the current study findings, Inter sphincteric fistula was observed in $48.88 \%$ cases whereas Trans-sphincteric fistula and Supra sphincteric fistula were $33.33 \%$ and $17.77 \%$ respectively. Among study participants, $44.44 \%$ 


\section{Original Research Article}

underwent Fistulectomy the proportions of Fistulotomy were $31.11 \%$ and insertion of cutting was done in $24.44 \%$. of cases. Like the current study in the study of Visscher et al [11], the proportion of of Inter sphincteric fistulas $(83.67 \%)$ were more than the trans-sphincteric and Supra sphincteric fistulas $(16.32 \%)$.

Our study findings show that there was an improvement in pre to post-operative Mean values of symptoms (49.50 vs 66.25) and the same type of results was found for associated physical disease (14.25 Vs 22.76), emotions (7.65 and 15.27), Social integration (8.26 Vs 14.40) whereas effects of treatment also showing 3.00 before treatment and 3.65 after treatment. Preoperative mean of GIQIL Total score was 89.05 and post-surgery was 120.26 with statistically significant mean difference $(\mathrm{P}=$ $<0.01$ ). Seneviratne SA et al [10], have reported significant difference between the average preoperative (97.02) and postoperative (116.14) GIQLI scores ( $\mathrm{P}<$ 0.01 ) in a group of patients undergoing surgery for recurrent fistula in ano. As per this study, the worst affected aspects were emotions, social integration and effects of treatment.

Like our study in the study of Leroy A et al [13] QOL of the patients was assessed by PFDI-20 and PFIQ-7 questionnaires and reported a significant decrease in stool incontinence and improved quality of life and their emotional state. preoperatively, $50 \%(2 / 4)$ of the patients reported anxiety compared to $0 \%(0 / 4)$ postoperatively $(\mathrm{P}=0.4)$. Similarly, $75 \%(3 / 4)$ complained of a decrease in their quality of life (social, sports, etc.) preoperatively compared with $0 \%(0 / 4)$ postoperatively $(\mathrm{P}>0.9)$.

In study by Owen et al [14], QOL was worse on two of eight SF-36 domains in patients with fistula in ano. Patients with recurrent disease, secondary extensions, urgency were associated with worse quality of life in multiple domains. Ortiz $\mathrm{H}$ et al [15] have reported an increase in the median (interquartile range) score in the CCF-FI scale from 0.00 before the intervention to 1 in the postoperative period $(\mathrm{p}=0.001)$.

Significant improvement was reported in physical functioning, role limitations-physical, bodily pain, vitality, social functioning and mental health. As per this study, No statistically significant differences were found in general health perception or in role limitationsemotional. Grucela, A. et al [2], have assessed QOL by the European QOL index (EQ-5D) and functional results with the Fecal Incontinence Severity Index (FISI) in patients with fistula in ano and other anorectal conditions. There was significant improvement in overall pain and QOL following surgery.
There is wide variation across the studies in the methodology, more specially the choice of tools used for assessment of QOL. This makes cross study comparison very difficult. But in spite of these differences, majority of the published studies have reported significant improvement in symptoms, and quality of life in different domains after surgical intervention for fistula in ano. This makes the role of surgical intervention highly impactful and indispensable in management of fistula in ano.

\section{Conclusions}

1. There is a significant improvement in the quality of life postoperatively in patients of Fistula in ano.

2. GIQLI score is a useful tool to assess the quality of life in Fistula in ano patients.

\section{Recommendations}

1. There is a need to develop a disease specific quality of life score to assess QoL in fistula in ano patients. This brings uniformity across the studies and hence make cross study comparisons more meaningful.

2. All possible efforts should be made by treating Health Care providers to make a positive impact on quality of life by providing appropriate intervention along with effective counselling of affected patients.

Conflict of interest: None declared. Funding: Nil, Permission from IRB: Yes

\section{References}

1. Parks AG, Gordon PH, Hardcastle JD. A classification of fistula-in-ano. Br J Surg. 1976 Jan;63(1):1-12.

2. Grucela A, Gurland B, Kiran RP. Functional outcomes and quality of life after anorectal surgery. Am Surg. 2012 Sep; 78(9):952-6.

3. Shouler P, Grimley R, Keighley M, AlexanderWilliams J. Fistula-in-ano is usually simple to manage surgically. International journal of colorectal disease. 1986;1(2):113-5.

4. Arroyo A, Pérez-Legaz J, Moya P, Armañanzas L, Lacueva J, Pérez-Vicente F, et al. Fistulotomy and sphincter reconstruction in the treatment of complex fistula-in-ano: long-term clinical and manometric results. Annals of surgery. 2012;255(5):935-9.

5. Garcia-Aguilar J, Belmonte C, Wong WD, Goldberg SM, Madoff RD. Anal fistula surgery. Factors associated with recurrence and incontinence. Dis Colon Rectum. 1996 Jul;39(7):723-9. 


\section{Original Research Article}

6. Lunniss P, Kamm M, Phillips R. Factors affecting continence after surgery for anal fistula. British journal of surgery. 1994;81(9):1382-5.

7. Wong S, Solomon M, Crowe P, Ooi K. Cure, continence and quality of life after treatment for fistula-inano. ANZ J Surg. 2008 Aug;78(8):675-82. doi: 10.1111/j. 1445-2197.2008.04616.x.

8. Sailer M, Bussen D, Debus ES, Fuchs KH, Thiede A. Quality of life in patients with benign anorectal disorders. Br J Surg. 1998 Dec;85(12):1716-9.

9. Eypasch E, Williams J, Wood-Dauphinee S, Ure B, Schmulling C, Neugebauer E, et al. Gastrointestinal Quality of Life Index: development, validation and application of a new instrument. British Journal of Surgery. 1995; 82(2):216-22.

10. Seneviratne SA, Samarasekera DN, Kotalawala W. Quality of life following surgery for recurrent fistula-inano. Tech Coloproctol. 2009 Sep;13(3):215-7. doi: 10. 1007 /s10151-009-0517-z. Epub 2009 Jul 18.

11. Visscher AP, Schuur D, Roos R, Van der Mijnsbrugge GJ, Meijerink WJ, Felt-Bersma RJ. Long-term follow-up after surgery for simple and complex cryptoglandular fistulas: fecal incontinence and impact on quality of life. Dis Colon Rectum. 2015 May;58(5):533-9. doi: 10. 1097 / DCR. 0000000000000352.

12. Eypasch E, Williams JI, Wood-Dauphinee S, Ure BM, Schmülling C, Neugebauer E, Troidl H. Gastrointestinal Quality of Life Index: development, validation and application of a new instrument. Br J Surg. 1995 Feb; 82 (2): 216-22.

13. Leroy A, Azais H, Giraudet G, Cosson M. [Quality of life and symptoms before and after surgical treatment of rectovaginal fistula]. Progres en urologie : journal de l'Association francaise d'urologie et de la Societe francaise d'urologie. 2017,10.1016/j.purol.2016.12.001.

14. Owen HA, Buchanan GN, Schizas A, Cohen R, Williams AB. Quality of life with anal fistula. Annals of the Royal College of Surgeons of England. 2016; 98 (5):334-8,10.1308/rcsann.2016.0136.

15. Ortiz H, Marzo J, Armendariz P, De Miguel M. Quality of life assessment in patients with chronic anal fissure after lateral internal sphincterotomy. Br J Surg. $2005 \mathrm{Jul} ;$ 92(7):881-5.

\section{How to cite this article?}

Chandrabose K, Nair V. Improvement in quality of life in patients with Fistula-In-Ano, following surgical management, a prospective observational study.Int J surg Orthopedics. 2017; 3(1):24-28.doi:10.17511/ijoso.2017.i01.05. 